Supporting Information

\title{
Discriminating the Role of Surface Hydride and Hydroxyl for Acetylene Semi- Hydrogenation over Ceria Through in situ Neutron and Infrared Spectroscopy
}

Jisue Moon†, Yongqiang Chengł, Luke L. Daemenł, Meijun Li †, Felipe Polo-Garzon广, Anibal

J. Ramirez-Cuestał, Zili Wu ${ }^{*}$

$\dagger$ Chemical Science Division, Oak Ridge National Laboratory, 1 Bethel Valley Road, Oak

Ridge, Tennessee, United state 37831-6475

$\ddagger$ Neutron Scattering Division, Oak Ridge National Laboratory, 1 Bethel Valley Road, Oak

Ridge, Tennessee, United state 37831-6475 


\section{Experimental Procedures}

\section{Recoil energy and effective mass calculation}

When recoil happens during a collision of a neutron with a single nucleus, the average energy gain of the nucleus depends on the momentum transfer of the neutron and the apparent inertia of the nucleus. It can be expressed as recoil energy ${ }^{1}$ :

$$
E_{r}=\frac{\hbar Q^{2}}{2 M}
$$

where $\hbar$ is Plank constant $/ 2 \pi, \mathrm{Q}$ is the momentum transfer, and $\mathrm{M}$ is the effective mass. It is found that when $\mathrm{M}$ equals to about $3 \mathrm{amu}$, the corresponding $\mathrm{Q}$ values in forward and backward scattering lead to peak positions at 5.5 and $32 \mathrm{~cm}^{-1}$, explaining the experimental observations very well.

Moreover, the peak profile due to recoil can be described by ${ }^{1}$ :

$$
S(Q, \omega)=\left(\frac{\beta}{4 \pi E_{r}}\right)^{1 / 2} \exp \left\{-\frac{\beta}{4 E_{r}}\left(\hbar \omega-E_{r}\right)^{2}\right\}
$$

where $\beta=1 / k_{B} T$. This means at higher recoil energy, one would expect broader peak and lower maximum intensity, which is again consistent with our observation.

\section{QMS data analysis}

When acetylene hydrogenation occurs, it is complicated to analyze the mass spectrometer data due to the similar fragmentation mass numbers between acetylene, ethylene, and ethane. Although the obtained mass numbers are similar, but each of them has a specific ratios of mass 
fragmentations. Before analyzing the reaction data, references of pure acetylene, ethylene and ethane were measured in both continuous and pulse modes to obtain the specific pattern matrix of each compound and responses for different mass numbers are listed in Table S1. The measurement of acetylene itself was at least repeated for 3 times without reaction. The mass number 26, 27, 30 were selected as representative mass number of acetylene, ethylene and ethane, respectively. It is selected based on the difference bigger than $10 \%$ among the three compounds.

For the reaction data, the QMS profiles of $\mathrm{m} / \mathrm{e}=26,27$, and 30 were specifically monitored. The raw data were then corrected using the ratio that was obtained from the mass fragment pattern analysis (Table S1) to reflect the ethylene and ethane formation. After the raw data were corrected, the area of each mass number was obtained by integrating the peak and using the equations from the experimental section, the conversion and selectivity were obtained.

\section{Results and Discussion}

Table S1. Mass fragment percentage (\%) for each compound obtained from continuous flow. Based on the ratio difference, $\mathrm{m} / \mathrm{e}=26,27,30$ were selected as a representative mass number of acetylene, ethylene and ethane, respectively.

\begin{tabular}{cccc}
\hline Mass & Acetylene & Ethylene & Ethane \\
\hline 12 & 2.01 & 1.38 & 0.43 \\
13 & 6.72 & 2.32 & 0.91 \\
14 & 0.37 & 5.55 & 3.23 \\
15 & 0.06 & 0.50 & 4.94
\end{tabular}




\begin{tabular}{cccc}
16 & 0.16 & 0.30 & 0.12 \\
20 & 0.32 & 0.37 & 0.10 \\
21 & 0.00 & 0.00 & 0.00 \\
22 & 0.01 & 0.00 & 0.00 \\
24 & 6.04 & 2.96 & 0.74 \\
25 & 21.59 & 9.08 & 3.70 \\
26 & 100.00 & 55.02 & 22.47 \\
27 & 2.08 & 56.06 & 32.14 \\
28 & 1.79 & 100.00 & 100.00 \\
29 & 0.03 & 1.91 & 21.14 \\
30 & 0.01 & 0.02 & 20.86 \\
\hline
\end{tabular}


(a) QMS profile for acetylene pulse over $\mathrm{CeO}_{2}-673 \mathrm{~K}-\mathrm{O}$

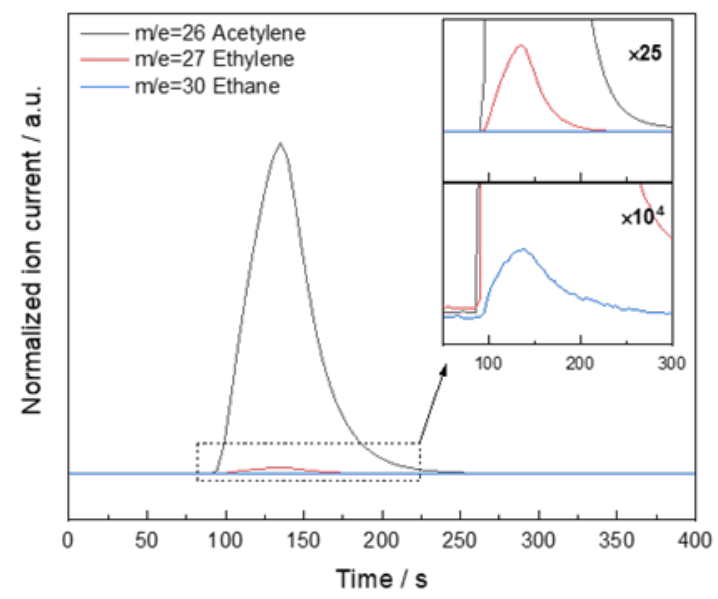

(b) QMS profile for acetylene pulse over $\mathrm{CeO}_{2}-673 \mathrm{~K}-\mathrm{H}$

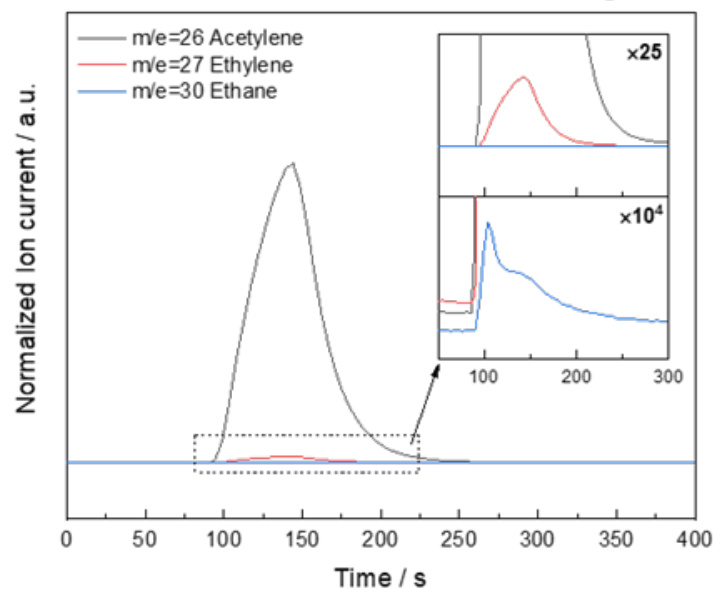

(c) QMS profile for acetylene pulse without catalyst

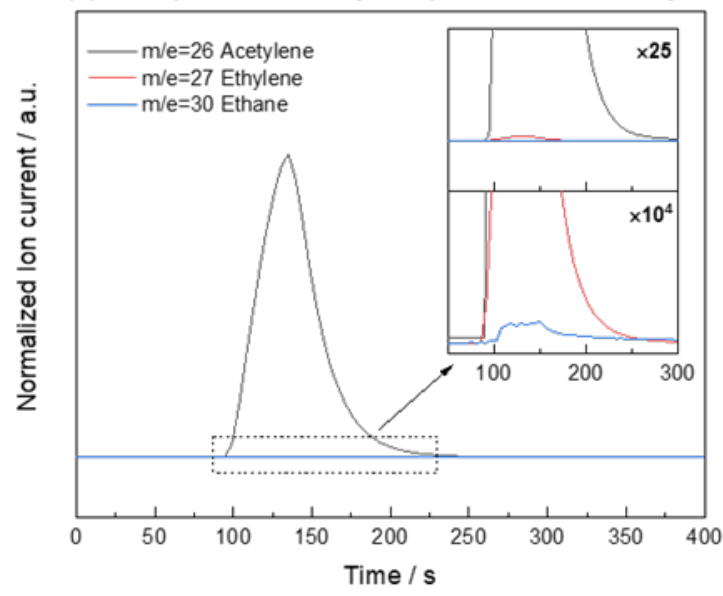

Figure S1. QMS profile obtained during in situ DRIFT-MS measurement of acetylene pulse over (a) $\mathrm{CeO}_{2}-673 \mathrm{~K}-\mathrm{O}$ and (b) $\mathrm{CeO}_{2}-673 \mathrm{~K}-\mathrm{H}$ after correcting the baseline and (c) bypass the IR cell. Note that the scale of each graph is the same. 

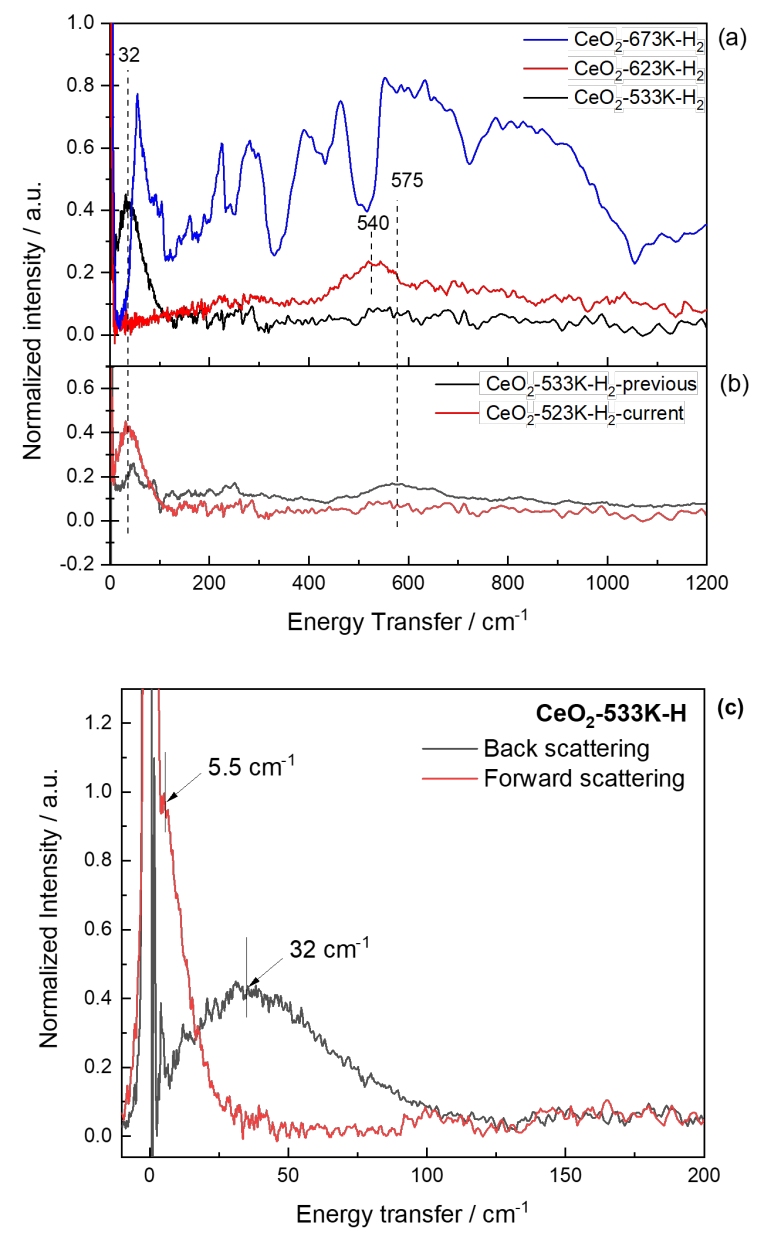

Figure S2. INS spectra of (a) $\mathrm{CeO}_{2}$ collected at $5 \mathrm{~K}$ after $\mathrm{H}_{2}$ treated at 533, 623, and $673 \mathrm{~K}$;

(b) $\mathrm{CeO}_{2}-533 \mathrm{~K}-\mathrm{H}$ from current and previous data reprinted from ref. S2. All spectra are difference spectra using the spectrum of $\mathrm{CeO}_{2}$ after $673 \mathrm{~K} \mathrm{O}_{2}$ treatment as a background. (c) Forward and back scattering comparison for hydrogen activation over $\mathrm{CeO}_{2}-533 \mathrm{~K}-\mathrm{H}$.

Figure S2 shows the spectra collected at $5 \mathrm{~K}$ after the ceria rods were treated with $\mathrm{H}_{2}$ at different temperatures $\left(533,623\right.$ and $673 \mathrm{~K}$ ) for $2 \mathrm{hrs}$ (denoted as $\mathrm{CeO}_{2}-533 \mathrm{~K}-\mathrm{H}, \mathrm{CeO}_{2}-623 \mathrm{~K}-\mathrm{H}$, and $\mathrm{CeO}_{2}-673 \mathrm{~K}-\mathrm{H}$, respectively). They are difference spectra between the measured spectra after the different treatments and the background spectrum of $\mathrm{CeO}_{2}$ after oxidation treatment at $673 \mathrm{~K}$ (denoted as $\mathrm{CeO}_{2}-673 \mathrm{~K}-\mathrm{O}$ ). In our previous work, after the $\mathrm{H}_{2}$ treatment at $533 \mathrm{~K}$, a weak 
feature centred around $575 \mathrm{~cm}^{-1}$ were observed and this is assigned to surface $\mathrm{OH}$ group on $\mathrm{CeO}_{2}$ 2.

To understand the origin of the peak at $32 \mathrm{~cm}^{-1}$, we compared the spectra collected on the forward scattering and backward scattering banks at VISION as shown in Figure S2 (c). At the same energy transfer, these two spectra correspond to two different momentum transfer (Q) with the backward scattering having high Q. At the elastic line, the Q values are $1.0 \AA^{-1}$ and $2.4 \AA^{-1}$ for the forward and backward scattering, respectively. For a typical vibrational mode, different Q often results in different peak intensities and sometimes minor differences in peak positions. However, comparison in Fig S2 (c) shows that the two spectra are drastically different at below $100 \mathrm{~cm}^{-1}$. In the forward scattering spectrum, a narrow and intense shoulder at $5.5 \mathrm{~cm}-1$ was observed, whereas in the back-scattering spectrum one can see a broad band centering around 32 $\mathrm{cm}^{-1}$. 


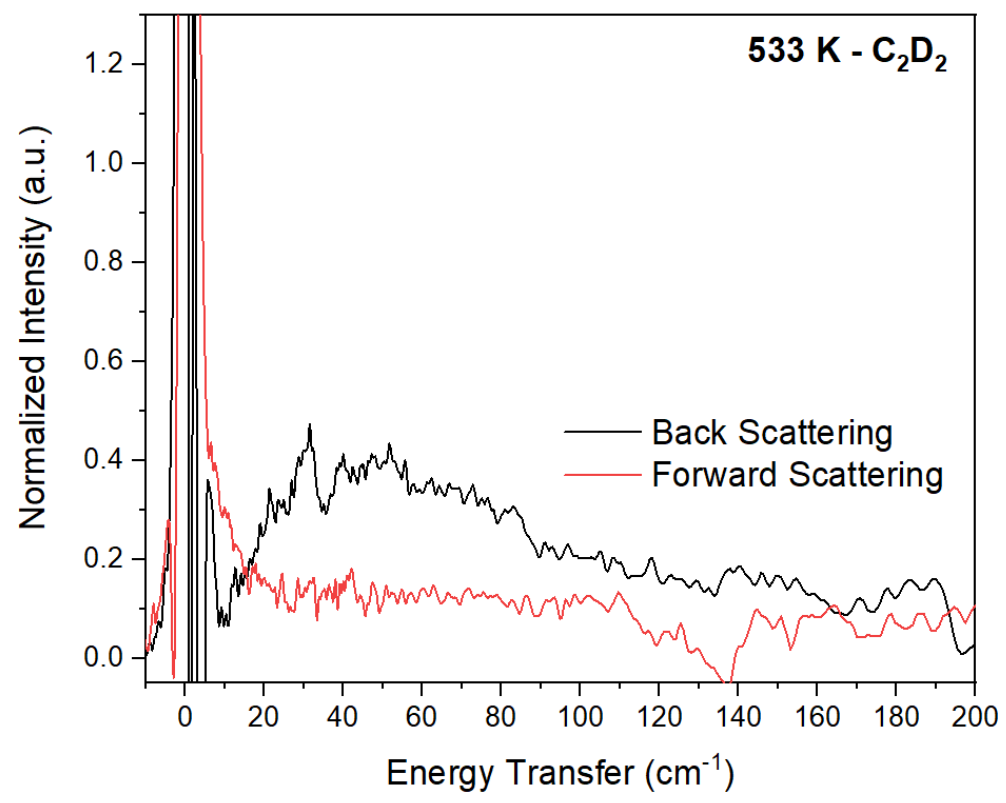

Figure S3. INS of forward and back scattering comparison from $\mathrm{C}_{2} \mathrm{D}_{2}$ reaction over $\mathrm{CeO}_{2}-533 \mathrm{~K}-$ $\mathrm{H}$ sample. The low energy peak at $50 \mathrm{~cm}^{-1}$ appears at a similar frequency to the recoil peak of atomic hydrogen $\left(\sim 32 \mathrm{~cm}^{-1}\right)$. However, their fundamental difference is revealed when comparing the backward and forward scattering here. In the case of $\mathrm{C}_{2} \mathrm{D}_{2}$ reacted sample, both spectra from the forward and backward scattering exhibit peaks at around $50 \mathrm{~cm}^{-1}$ (with different intensities), consistent with regular vibrational modes and the peak at $5.5 \mathrm{~cm}^{-1}$ from the forward scattering disappeared. 


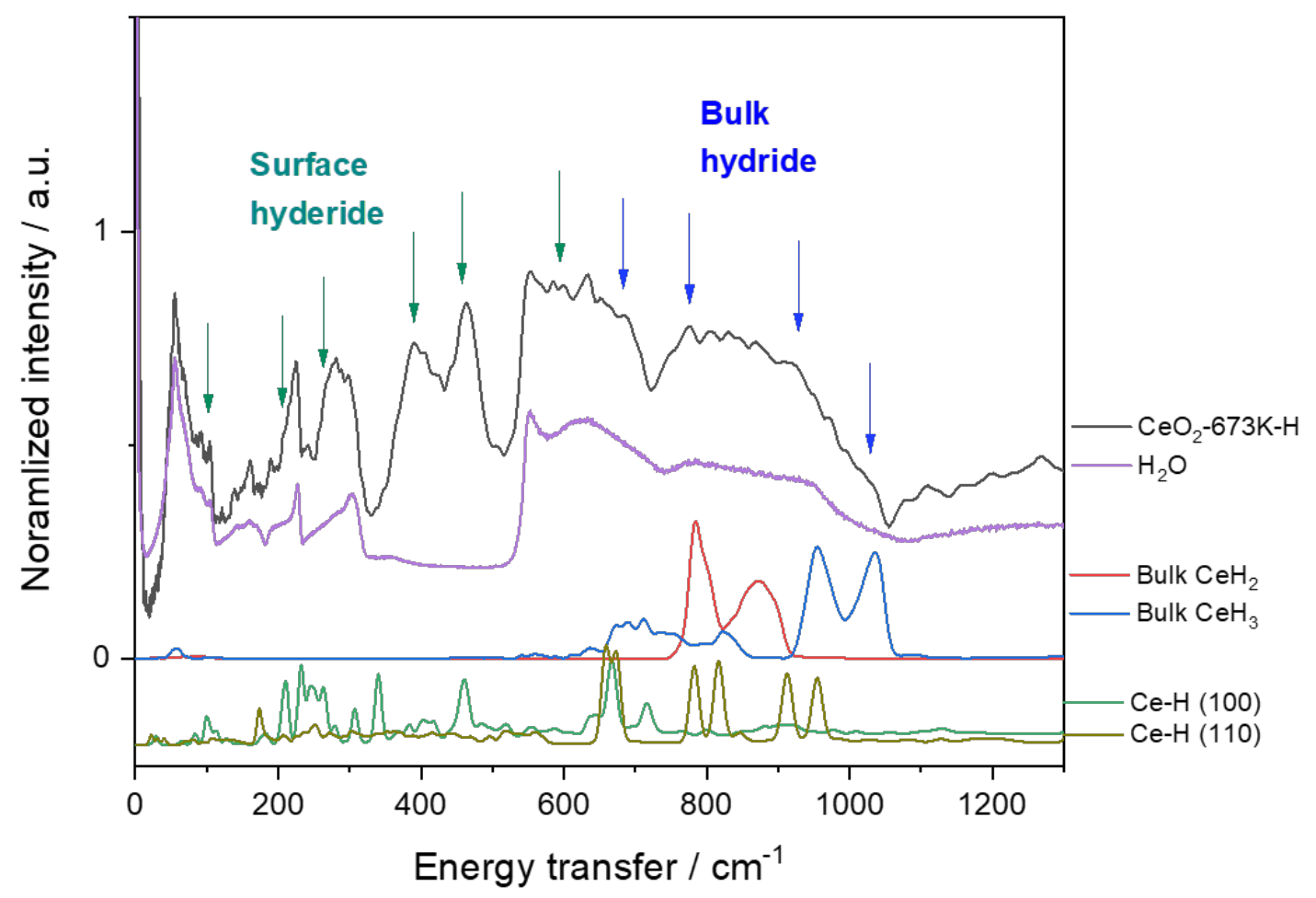

Figure S4. INS spectra of $\mathrm{CeO}_{2}$ collected at $5 \mathrm{~K}$ after $\mathrm{H}_{2}$ treated at $673 \mathrm{~K}$ with measure water spectrum to compare the spectrum with $\mathrm{CeO} 2-673 \mathrm{~K}-\mathrm{H}$. Additional surface hydride(Ce-H (100) and $\mathrm{Ce}-\mathrm{H}(110))$ and bulk hydride $\left(\mathrm{CeH}_{2}\right.$, and $\left.\mathrm{CeH}_{3}\right)$ has been compared to specify the location of surface hydride and bulk hydride. 


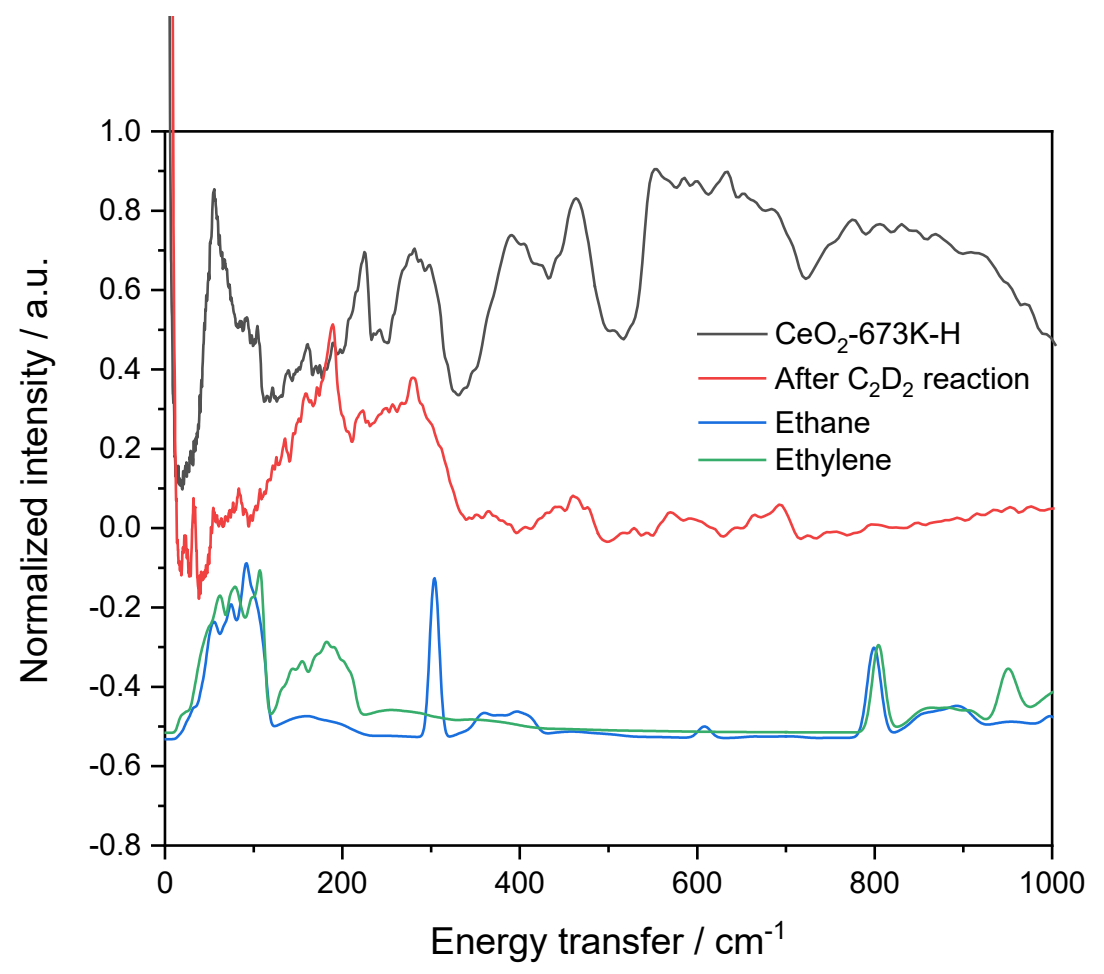

Figure S5. INS spectra of $\mathrm{CeO}_{2}-673 \mathrm{~K}-\mathrm{H}$ (black) and after $\mathrm{C}_{2} \mathrm{D}_{2}$ reaction (red). The calculated INS spectra of ethane (blue) and ethylene (green) have been added for comparison. 


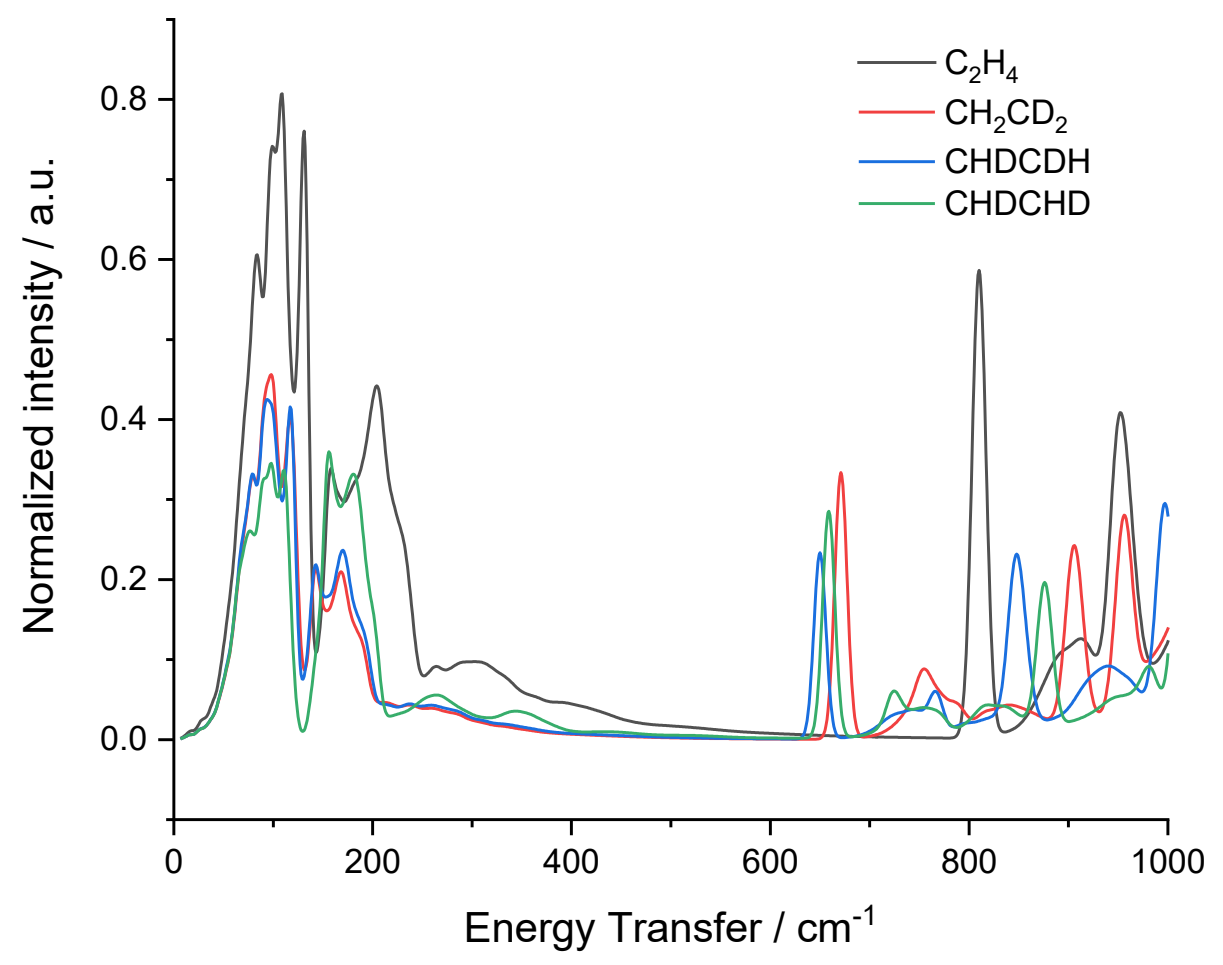

Figure S6. Simulated INS spectra of gas phase $\mathrm{C}_{2} \mathrm{H}_{4}, \mathrm{CH}_{2} \mathrm{CD}_{2}, \mathrm{CHDCDH}, \mathrm{CHDCHD}$. 


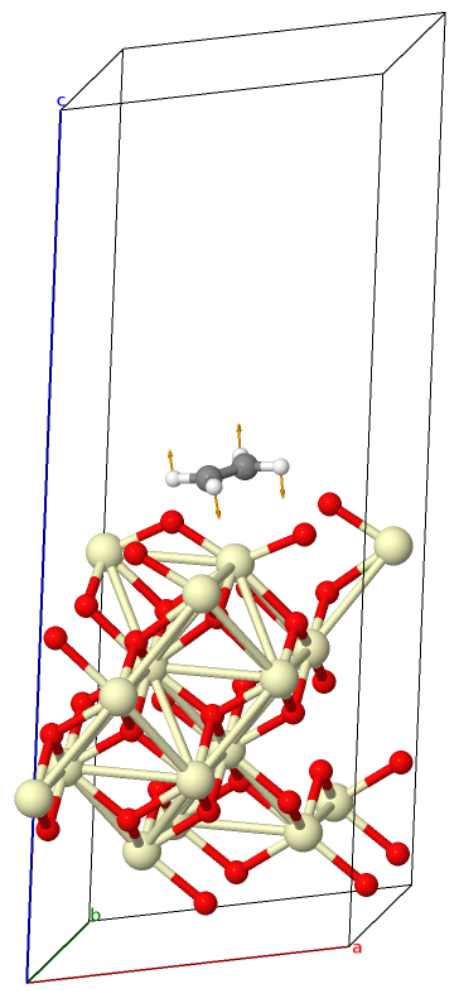

Figure S7. Calculated flapping mode of ethylene on ceria (100) surface (frequency close to 300 $\left.\mathrm{cm}^{-1}\right)$. 

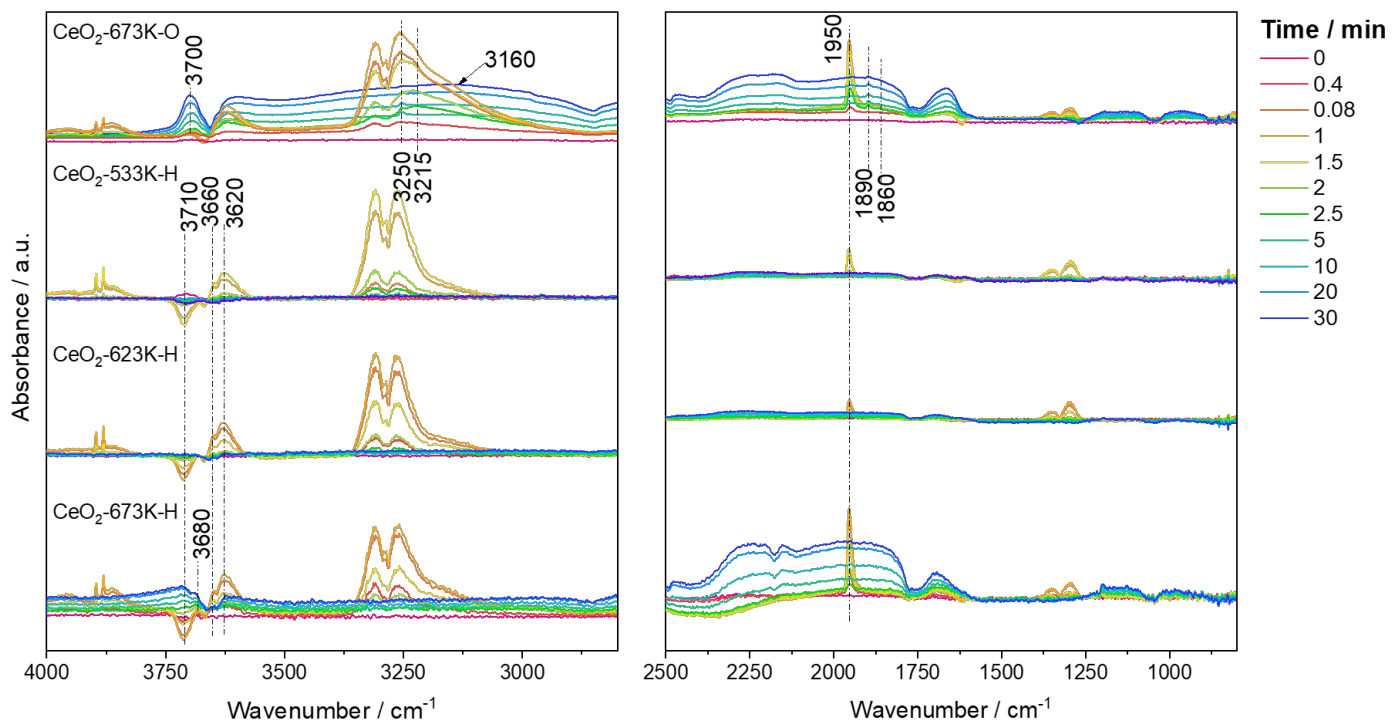

Figure S8. Full time scale (0 to $30 \mathrm{~min}$, bottom to top of each panel) of IR spectra collected during acetylene adsorption at room temperature over differently treated ceria surfaces 

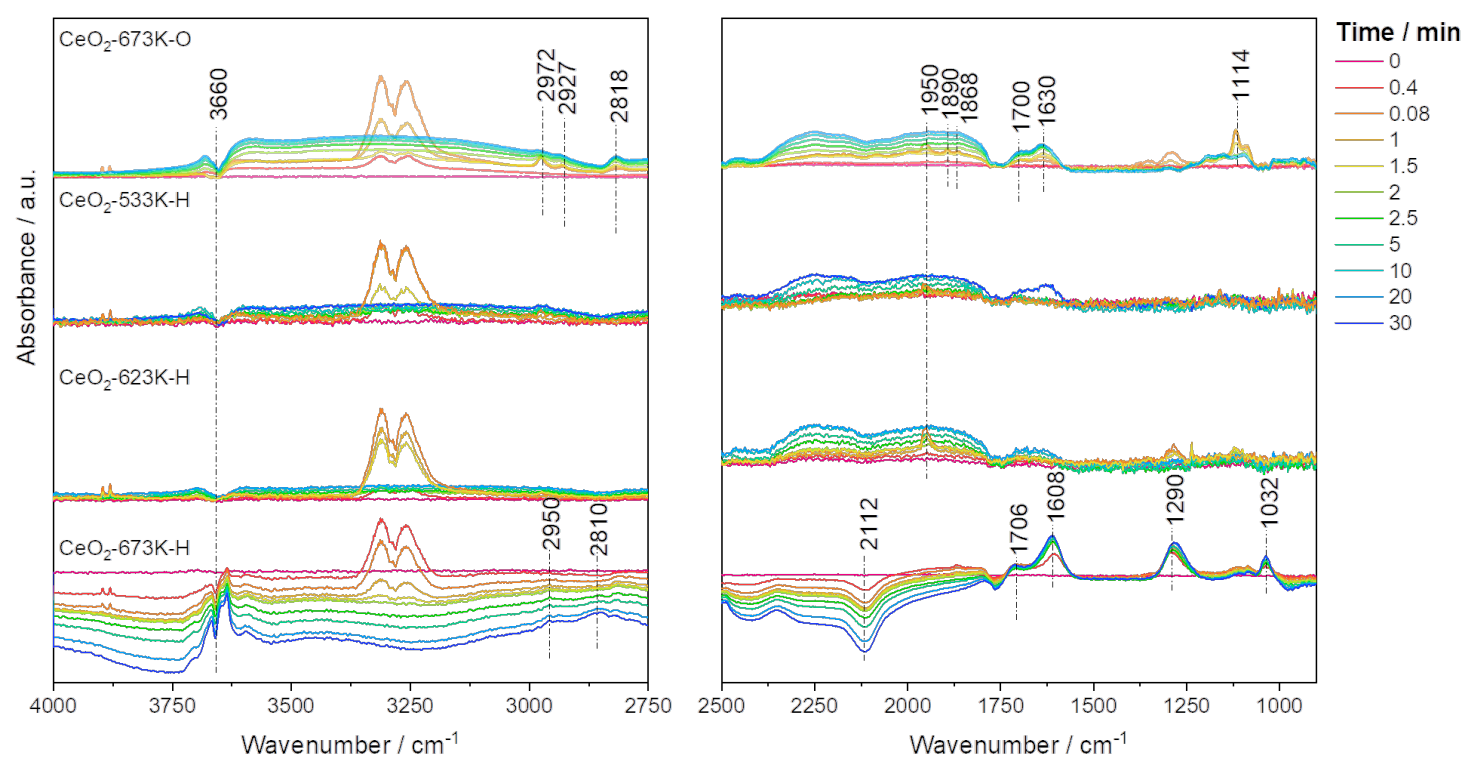

Figure S9. Full time scale (0 to $30 \mathrm{~min}$, bottom to top of each panel) of IR spectra collected during acetylene adsorption at $423 \mathrm{~K}$ over differently treated ceria surfaces

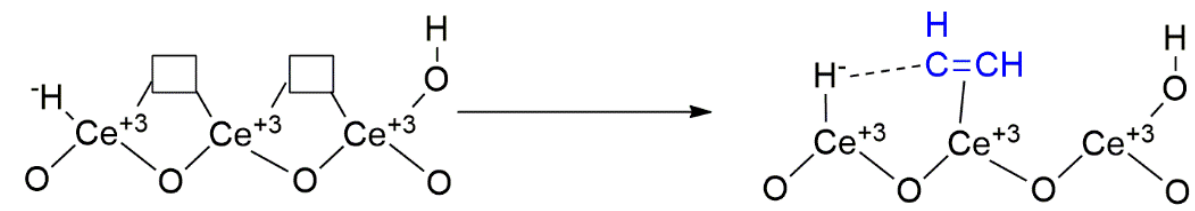

Figure S10. Scheme of hydride addition into acetylene over reduced ceria surface. 


\section{References}

S1. Squires, G. L., Introduction to the theory of thermal neutron scattering. Cambridge university press: 2012 .

S2. Wu, Z.; Cheng, Y.; Tao, F.; Daemen, L.; Foo, G. S.; Nguyen, L.; Zhang, X.; Beste, A.; Ramirez-Cuesta, A. J., Direct Neutron Spectroscopy Observation of Cerium Hydride Species on a Cerium Oxide Catalyst. J. Am. Chem. Soc. 2017, 139 (28), 9721-9727. 